\title{
Rollback Operation
}

National Cancer Institute

\section{Source}

National Cancer Institute. Rolliback Operation. NCI Thesaurus. Code C73938.

A command to cancel a business process and return a record to its previous state. 